\title{
Effect of Ambient Atmosphere and Temperature on The Corrosion Resistance of X80 High-deformation Pipeline Steel in Bicarbonate Solution
}

\author{
Wei Zhao ${ }^{1, *}$, Hui Zhang ${ }^{1}$, Yong Zou ${ }^{2}$ \\ ${ }^{1}$ School of mechanical \& automotive engineering, Qilu University of Technology, Jinan 250353, \\ China \\ ${ }^{2}$ Key Laboratory for Liquid-Solid Structural Evolution \& Processing of Materials Ministry of \\ Education, Shandong University, Jinan 250061, China \\ *E-mail: zwapple@yeah.net
}

doi: $10.20964 / 2017.01 .90$

Received: 19 September 2016 / Accepted: 14 November 2016 / Published: 12 December 2016

\begin{abstract}
In this study, the electrochemical corrosion behavior of X80 high-deformation pipeline steel in bicarbonate solutions was evaluated. Effects of atmosphere and temperature on the corrosion resistance were studied by electrochemical tests. Results showed that the main characteristics of the potentiodynamic polarization curves are mainly determined by the atmosphere. The solution concentration and temperature can only affect the specific values. The presence of $\mathrm{O}_{2}$ can accelerate the corrosion reactions, resulting in "double-anodic-peak-phenomenon". $\mathrm{CO}_{2}$ weakens the stability of passivity, even eliminates the passivity phenomenon in dilute solution. Results of the potentiodynamic polarization, electrochemical impedance spectroscopy, potentiostatic anodic polarization, and MottSchottky analysis indicated that the corrosion rate increases and the passivity stability weakens, with the increase in temperature.
\end{abstract}

Keywords: X80 high deformation pipeline steel; corrosion resistance; atmosphere; temperature; passivity

\section{$\underline{\text { FULL TEXT }}$}

(C) 2017 The Authors. Published by ESG (www.electrochemsci.org). This article is an open access article distributed under the terms and conditions of the Creative Commons Attribution license (http://creativecommons.org/licenses/by/4.0/). 